\title{
Highly efficient oxygen evolution and stable water splitting by coupling NiFe LDH with metal phosphides
}

\author{
Chengye Song ${ }^{1,2 \dagger}$, Yi Liu ${ }^{1 \dagger}$, Yuchao Wang ${ }^{1,4 \dagger}$, Shuaihao Tang ${ }^{1,5}$, Wenkui $\mathrm{Li}^{2^{*}}$, Qian $\mathrm{Li}^{1,4}$, Jian Zeng ${ }^{1,5}$, \\ Lei Chen ${ }^{3}$, Hongcheng Peng ${ }^{3}$ and Yongpeng Lei ${ }^{1,3,6^{*}}$
}

\begin{abstract}
It is a great challenge to develop highly active oxygen evolution reaction (OER) electrocatalysts with superior durability. In this study, a NiFe layered double hydroxidedecorated phosphide ( $\mathrm{NiFe} \mathrm{LDH} @ \mathrm{CoP} / \mathrm{NiP}_{3}$ ) was constructed to display satisfactory OER activity and good stability for water splitting in alkaline media. At an overpotential of $300 \mathrm{mV}$, NiFe LDH@CoP/NiP $\mathrm{N}_{3}$ achieved a current density of $82 \mathrm{~mA} \mathrm{~cm}^{-2}$ for the OER, which was 9.1 and 2.3 times that of $\mathrm{CoP} / \mathrm{NiP}_{3}$ and $\mathrm{NiFe} \mathrm{LDH}$, respectively. Moreover, the reconstruction behavior, during which oxyhydroxides formed, was studied by a combination of $\mathrm{X}$-ray photoelectron spectroscopy, Raman spectroscopy, and scanning electron microscopy. A synergistic effect between $\mathrm{NiFe} \mathrm{LDH}$ and $\mathrm{CoP} / \mathrm{NiP}_{3}$ was also observed for the hydrogen evolution reaction. Furthermore, when NiFe $\mathrm{LDH} @ \mathrm{CoP} / \mathrm{NiP}_{3}$ acted as both the cathode and anode for overall water splitting, a high current density of $100 \mathrm{~mA} \mathrm{~cm}^{-2}$ was maintained for more than $275 \mathrm{~h}$. In addition, under Xe light irradiation, a solar-to-hydrogen efficiency of $9.89 \%$ was achieved for solar-driven water splitting. This work presents the coupling of different active compositions, and can provide a reference for designing bifunctional electrocatalysts.
\end{abstract}

Keywords: bifunctional electrocatalysis, oxygen evolution reaction, phosphides, layered double hydroxides, water splitting

\section{INTRODUCTION}

Efficient electrocatalytic overall water splitting is expected to alleviate the increasingly severe energy shortage and environmental crisis [1-4]. However, the slow kinetics of the oxygen evolution reaction (OER) and poor durability of catalysts under alkaline conditions [5-8]. Although $\mathrm{RuO}_{2}, \mathrm{IrO}_{2}$ and others have been utilized, there is an urgent necessity to develop earth-abundant OER catalysts with high activity, good stability, and low cost [9-12]. In previous studies, a series of OER catalysts in alkaline solutions have been developed, including metal oxides $[13,14]$, hydroxides [15], selenides [16], sulfides [17,18], carbides [19], phosphides [20,21], and others [22-24]. Although phosphides generally show good hydrogen evolution reaction (HER) activity because of their similar catalytic mechanism to that of hydrogenase [25], their OER activities are unsatisfactory. Additionally, during the OER, phosphides are usually converted to oxyhydroxides, which are considered to be real active sites [26]. The investigation of reconstruction behavior requires more attention [27].

In contrast, layered double hydroxides (LDHs) are regarded as excellent OER catalyst candidates [28,29]. They have large specific surface areas and porous structures, which are beneficial for increasing the number of active sites and promoting mass transfer. However, because of their weak hydrogen adsorption, LDHs exhibit relatively poor HER activity, thus hindering their potential as bifunctional OER/HER catalysts. Synergistic effects play important roles in boosting bifunctional performance, such as in the OER/HER [30]. Yang et al. [31] decorated $\mathrm{LDH}$ with $\mathrm{CoNiSe}_{2}$ to adjust $\mathrm{H}_{2} \mathrm{O}$ chemisorption and

\footnotetext{
${ }^{1}$ State Key Laboratory of Powder Metallurgy, Central South University, Changsha 410083, China

${ }^{2}$ School of Materials and Mechanical Engineering, Jiangxi Key Laboratory of Surface Engineering, Jiangxi Science and Technology Normal University, Nanchang 330013, China

${ }^{3}$ Hunan Provincial Key Laboratory of Chemical Power Sources, College of Chemistry and Chemical Engineering, Central South University, Changsha 410083, China

${ }^{4}$ School of Material Science and Engineering, Central South University of Forestry and Technology, Changsha 410004, China

${ }^{5}$ Energy Materials Computing Center, Jiangxi University of Science and Technology, Nanchang 330013, China

${ }^{6}$ State Key Laboratory of Advanced Chemical Power Sources, Guizhou Meiling Power Sources Co. Ltd., Zunyi 563003, China

† These authors contributed equally to this work.

*Corresponding authors (emails: lypkd@163.com (Lei Y); liwenkui1976@163.com (Li W))
} 
produce reactive $\mathrm{H}$ intermediates, thus leading to efficient overall water splitting. Liang et al. [32] electrodeposited amorphous $\mathrm{NiFe}$ hydroxides onto a $\mathrm{NiFeP}$ surface to construct a hybrid structure. The resulting electronic interactions boosted water oxidation by lowering the adsorption energy of $\mathrm{H}_{2} \mathrm{O}$. Thus, it could be proposed that metal phosphides and NiFe LDH may compensate each other's weaknesses when combined, achieving bifunctional OER/HER activity $[33,34]$.

In this study, we coupled NiFe LDH with metal phosphides to boost the OER activity and stability of water splitting in alkaline media. For the OER, at an overpotential of $300 \mathrm{mV}, \mathrm{NiFe} \mathrm{LDH} @ \mathrm{CoP} / \mathrm{NiP}_{3}$ achieved a current density of $82 \mathrm{~mA} \mathrm{~cm}^{-2}$, which was 9.1 and 2.3 times that of $\mathrm{CoP} / \mathrm{NiP}_{3}$ and NiFe $\mathrm{LDH}$, respectively. The reconstruction behavior during the OER was also studied. As both the cathode and anode in an electrolytic cell, NiFe LDH@CoP/NiP ${ }_{3}$, demonstrated robust stability for $275 \mathrm{~h}$ at a high current density of $100 \mathrm{~mA} \mathrm{~cm}^{-2}$. Using the simulated solar illumination, water splitting driven by solar cells achieved a solar-to-hydrogen (STH) efficiency of $9.89 \%$.

\section{EXPERIMENTAL SECTION}

\section{Materials}

$\mathrm{Fe}\left(\mathrm{NO}_{3}\right)_{3} \cdot 9 \mathrm{H}_{2} \mathrm{O}, \mathrm{Ni}\left(\mathrm{NO}_{3}\right)_{2} \cdot 6 \mathrm{H}_{2} \mathrm{O}, \mathrm{CO}\left(\mathrm{NH}_{2}\right)_{2}, \mathrm{NaH}_{2} \mathrm{PO}_{2}$. $\mathrm{H}_{2} \mathrm{O}$ and $\mathrm{NH}_{4} \mathrm{~F}$ were purchased from Sinopharm Chemical Reagent Co, Ltd. (SCRC). $\mathrm{Co}\left(\mathrm{NO}_{3}\right)_{2} \cdot 6 \mathrm{H}_{2} \mathrm{O}$ and $\mathrm{C}_{3} \mathrm{H}_{4} \mathrm{~N}_{2}$ were purchased from Shanghai Macklin Biochemical Co, Ltd. All the reagents were of analytical grade and used directly without further purification.

\section{Preparation of the catalysts}

Synthesis of $\mathrm{CoP} / \mathrm{NiP}_{3}$

Firstly, $\mathrm{Co}\left(\mathrm{NO}_{3}\right)_{2} \cdot 6 \mathrm{H}_{2} \mathrm{O}(1 \mathrm{mmol}), \mathrm{NH}_{4} \mathrm{~F}(5 \mathrm{mmol})$ and $\mathrm{CO}\left(\mathrm{NH}_{2}\right)_{2}(5 \mathrm{mmol})$ were mixed and dissolved in $30 \mathrm{~mL}$ deionized (DI) water. Before hydrothermal reaction, $\mathrm{Ni}$ foams were successively cleaned with $3 \mathrm{~mol} \mathrm{~L}^{-1} \mathrm{HCl}$, ethanol, and pure water under ultrasonication for $15 \mathrm{~min}$ to remove surface oxides and impurity. The mixture and a piece of $\mathrm{Ni}$ foam $\left(2 \times 1 \mathrm{~cm}^{2}\right)$ were shifted to Teflonlined stainless-steel autoclave and warmed up to $120^{\circ} \mathrm{C}$ and maintained for $8 \mathrm{~h}$. The precursor was washed with DI water and ethanol for three times and dried in vacuum at $60^{\circ} \mathrm{C}$. Secondly, $\mathrm{C}_{3} \mathrm{H}_{4} \mathrm{~N}_{2}(0.30 \mathrm{~g})$ and the as-prepared precursor were put on the upper and downstream of quartz boat, respectively. Then the obtained sample was calcined to $280^{\circ} \mathrm{C}\left(2^{\circ} \mathrm{C} \mathrm{min}^{-1}\right)$ and maintained for $2 \mathrm{~h}$ in
$\mathrm{N}_{2}$. Next, phosphorization was realized at $260^{\circ} \mathrm{C}$ under the condition of the second step except using $\mathrm{NaH}_{2} \mathrm{PO}_{2}$. $\mathrm{H}_{2} \mathrm{O}$.

Synthesis of NiFeLDH@CoP/NiP 3 The synthesis of NiFe LDH was referred to literature [34]. $\mathrm{Fe}\left(\mathrm{NO}_{3}\right)_{3} \cdot 9 \mathrm{H}_{2} \mathrm{O}(0.25 \mathrm{mmol}), \mathrm{Ni}\left(\mathrm{NO}_{3}\right)_{2} \cdot 6 \mathrm{H}_{2} \mathrm{O}(0.75 \mathrm{mmol})$ and $\mathrm{CO}\left(\mathrm{NH}_{2}\right)_{2}(1.25 \mathrm{mmol})$ were mixed and dissolved in $30 \mathrm{~mL}$ DI water. The mixture and the above $\mathrm{CoP} / \mathrm{NiP}_{3}$ $\left(2 \times 1 \mathrm{~cm}^{2}\right)$ were shifted to a Teflon-lined stainless-steel autoclave and warmed up to $120^{\circ} \mathrm{C}$ and maintained for $10 \mathrm{~h}$. The sample was washed with DI water and ethanol for three times and dried in vacuum at $60^{\circ} \mathrm{C}$.

\section{Synthesis of NiFe LDH}

NiFe LDH was synthesized by the similar process as $\mathrm{NiFe}$ $\mathrm{LDH} @ \mathrm{CoP} / \mathrm{NiP}_{3} . \mathrm{Fe}\left(\mathrm{NO}_{3}\right)_{3} \cdot 9 \mathrm{H}_{2} \mathrm{O}(0.25 \mathrm{mmol}), \mathrm{Ni}\left(\mathrm{NO}_{3}\right)_{2}$. $6 \mathrm{H}_{2} \mathrm{O}(0.75 \mathrm{mmol})$ and $\mathrm{CO}\left(\mathrm{NH}_{2}\right)_{2}(1.25 \mathrm{mmol})$ were mixed and dissolved in $30 \mathrm{~mL}$ DI water. Then, the mixture and a piece of treated $\mathrm{Ni}$ foam $\left(2 \times 1 \mathrm{~cm}^{2}\right)$ instead of $\mathrm{CoP} / \mathrm{NiP}_{3}$ were shifted to a Teflon-lined stainless-steel autoclave and warmed up to $120^{\circ} \mathrm{C}$ and maintained for $10 \mathrm{~h}$. The sample was washed with DI water and ethanol for three times and dried in vacuum at $60^{\circ} \mathrm{C}$.

\section{Characterizations}

The crystalline structures were tested by X-ray diffraction (XRD) on D/max $2550 \mathrm{VB}$ with $40 \mathrm{kV}$ and $\mathrm{Cu} \mathrm{Ka}$ radiation $(\lambda=1.5418 \AA)$. The morphology of the samples was characterized by a field emission scanning electron microscope (FE-SEM, Quanta 250 FEG) and transmission electron microscope (FE-TEM, FEI Tecnai G2 F20). Xray photoelectron spectroscopy (XPS) measurements were performed on Thermo Fisher Scientific K-Alpha with a monochromatic Al-Ka X-ray source. All XPS spectra were calibrated by shifting the detected adventitious $\mathrm{C}$ 1s peak to $284.4 \mathrm{eV}$. Raman spectra were measured by the Horibajylabram HR Evolution with a 532-nm excitation laser.

\section{Electrochemical test}

OER and HER tests were performed in a three-electrode system of an electrochemical station (CHI 660E) at room temperature. A graphite rod and a saturated calomel electrode (SCE) were used as the counter electrode and the reference electrode, respectively. The prepared $\mathrm{NiFe}$ $\mathrm{LDH} @ \mathrm{CoP} / \mathrm{NiP}_{3}$ was directly used as the work electrode without further treatment. The reference electrode is converted into a potential relative to the reversible hydrogen electrode (RHE): $E(\mathrm{RHE})=E(\mathrm{SCE})+0.2415+$ 
$0.0591 \times \mathrm{pH}$. The water splitting was conducted in $1 \mathrm{~mol} \mathrm{~L}^{-1} \mathrm{KOH}$ through a two-electrode system which employed NiFe LDH@CoP/NiP 3 as both cathode and anode. All the linear sweep voltammetry (LSV) of HER, OER and water splitting were tested at the sweep rate of $2 \mathrm{mV} \mathrm{s}^{-1}$ with $90 \%$ internal resistance (IR) compensation.

For the solar-driven water splitting, the STH efficiency can be defined as the following equation:

STH $(\%)=$ Chemical energy output/Solar energy input $=j \times A \times E_{\mathrm{f}} \times \mathrm{FE}_{\mathrm{H}_{2}} /\left(P_{\mathrm{s}} \times A\right)$,

where $j$ represents the operating current density; $A$ represents the effective illuminated area; $E_{\mathrm{f}}$ is the standard thermodynamic potential difference between HER and OER $(1.23 \mathrm{~V}) . \mathrm{FE}_{\mathrm{H}_{2}}$ is the Faradic efficiency of HER which is regarded as $100 \% ; P_{\mathrm{s}}$ is the power of simulated solar illumination $\left(100 \mathrm{~mW} \mathrm{~cm}^{-2}\right)$.

\section{RESULTS AND DISCUSSION}

To realize the composite of $\mathrm{CoP} / \mathrm{NiP}_{3}$ and $\mathrm{NiFe} \mathrm{LDH}$, $\mathrm{CoP} / \mathrm{NiP}_{3}$ was synthesized, followed by the growth of $\mathrm{NiFe}$ LDH (Fig. S1). The specific quantities of raw materials are stated in Table S1. XRD patterns were recorded to obtain crystallographic information (Fig. 1a). Table S2 summarizes the peaks for $\mathrm{NiFe} \mathrm{LDH} @ \mathrm{CoP} / \mathrm{NiP}_{3}$ and their attributions. The peaks located at $2 \theta=45.1^{\circ}, 52.3^{\circ}$ and $76.8^{\circ}$ correspond to the (111), (200), and (220) crystallographic planes of metallic Ni (PDF\#03-1051), respectively. The peaks at $2 \theta=21.4^{\circ}$ and $39.4^{\circ}$ indicate the presence of nickel hydroxides (PDF\#73-1520). The peak at $2 \theta=36.1^{\circ}$ corresponds to the (111) crystallographic plane of CoP (PDF\#29-0497). The peaks at $16.0^{\circ}$ and $36.3^{\circ}$ correspond to the (200) and (013) crystallographic planes of $\mathrm{NiP}_{3}$ (PDF\#73-1242), respectively. XPS was then conducted to determine the surface composition and chemical valence (Figs S2-S7). As shown in Fig. 1b, NiFe $\mathrm{LDH} @ \mathrm{CoP} / \mathrm{NiP}_{3}$ presents peaks corresponding to $\mathrm{Fe}, \mathrm{Co}$,
$\mathrm{Ni}, \mathrm{C}, \mathrm{P}$ and $\mathrm{O}$. The coexistence of $\mathrm{Fe}$ and $\mathrm{P}$ illustrates that NiFe LDH@CoP/NiP 3 was successfully obtained. The element contents are stated in Table S3. We noted that the Fe content was only $0.1 \mathrm{wt} \%$, which may suggest the low NiFe LDH content. Due to the low contents of Fe and $\mathrm{Ni}$ in the raw materials, the relative content of $\mathrm{NiFe} \mathrm{LDH}$ was low; this explains the lack of recognizable characteristic peaks associated with $\mathrm{NiFe} \mathrm{LDH}$ in the XRD patterns. Additionally, a weak peak at $26.6^{\circ}$, attributed to amorphous carbon, was observed, which resulted from small quantities of $\mathrm{CO}\left(\mathrm{NH}_{2}\right)_{2}$ and $\mathrm{C}_{3} \mathrm{H}_{4} \mathrm{~N}_{2}$ in the raw materials $[35,36]$.

In the SEM images (Fig. 2a and Fig. S8), NiFe $\mathrm{LDH} @ \mathrm{CoP} / \mathrm{NiP}_{3}$ shows an arborized structure (a typical characteristic of metal phosphides) on $\mathrm{Ni}$ foam. This structure could facilitate intimate contact between the catalyst and electrolyte to boost the OER kinetics [37]. The energy dispersive spectra (EDS) of NiFe LDH@CoP/ $\mathrm{NiP}_{3}$ also supported the presence of $\mathrm{Fe}, \mathrm{Co}, \mathrm{Ni}, \mathrm{C}, \mathrm{P}$, etc. (Fig. S9), in accordance with the XPS spectra. Furthermore, the uniform distribution of these elements was confirmed by the TEM elemental mapping images (Fig. 2b, c). Fig. 2d presents the morphology of $\mathrm{NiFe}$ $\mathrm{LDH} @ \mathrm{CoP} / \mathrm{NiP}_{3}$. The phosphides were decorated with thin LDH nanosheets. The high-resolution TEM images (Fig. 2e, f) show the presence of $\mathrm{CoP}$ and $\mathrm{NiP}_{3}$ particles. The clear crystal planes with $d$-spacing of 0.248 and $0.208 \mathrm{~nm}$ correspond to the (111) plane of CoP and the (321) plane of $\mathrm{NiP}_{3}$, respectively.

The OER performance was evaluated in $1 \mathrm{~mol} \mathrm{~L}^{-1} \mathrm{KOH}$ solution (Fig. 3a). As shown, $\mathrm{NiFe} \mathrm{LDH} @ \mathrm{CoP} / \mathrm{NiP}_{3}$ only required an overpotential of $239 \mathrm{mV}$ to drive $10 \mathrm{~mA} \mathrm{~cm}^{-2}$, outperforming its isolated $\mathrm{NiFe} \mathrm{LDH} \mathrm{and}$ $\mathrm{CoP} / \mathrm{NiP}_{3}$ counterparts [38]. At a large current density of $100 \mathrm{~mA} \mathrm{~cm}{ }^{-2}$, NiFe LDH@CoP/NiP 3 also displayed a significant overpotential advantage $(310 \mathrm{mV})$ compared
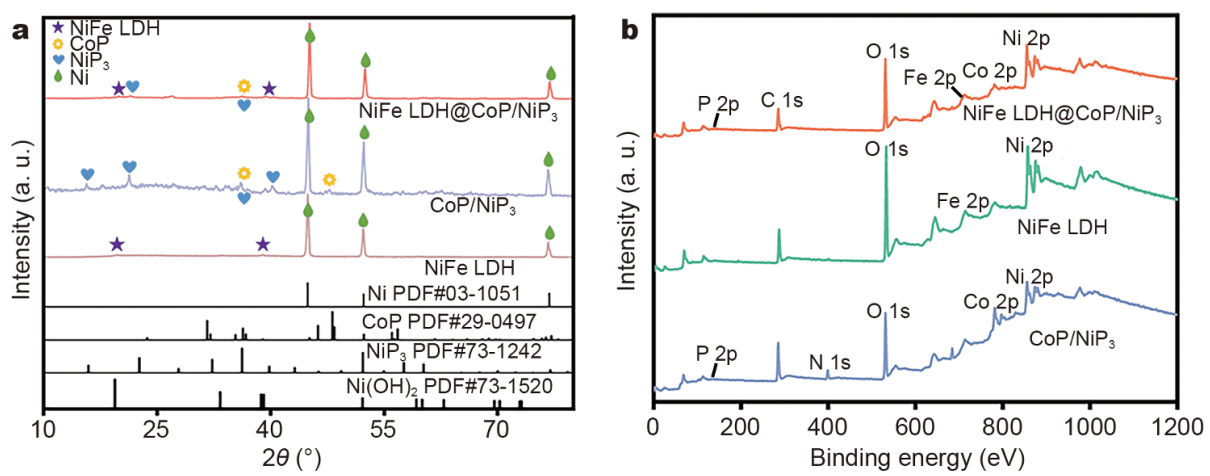

Figure 1 (a) XRD patterns and (b) XPS survey of various samples. 

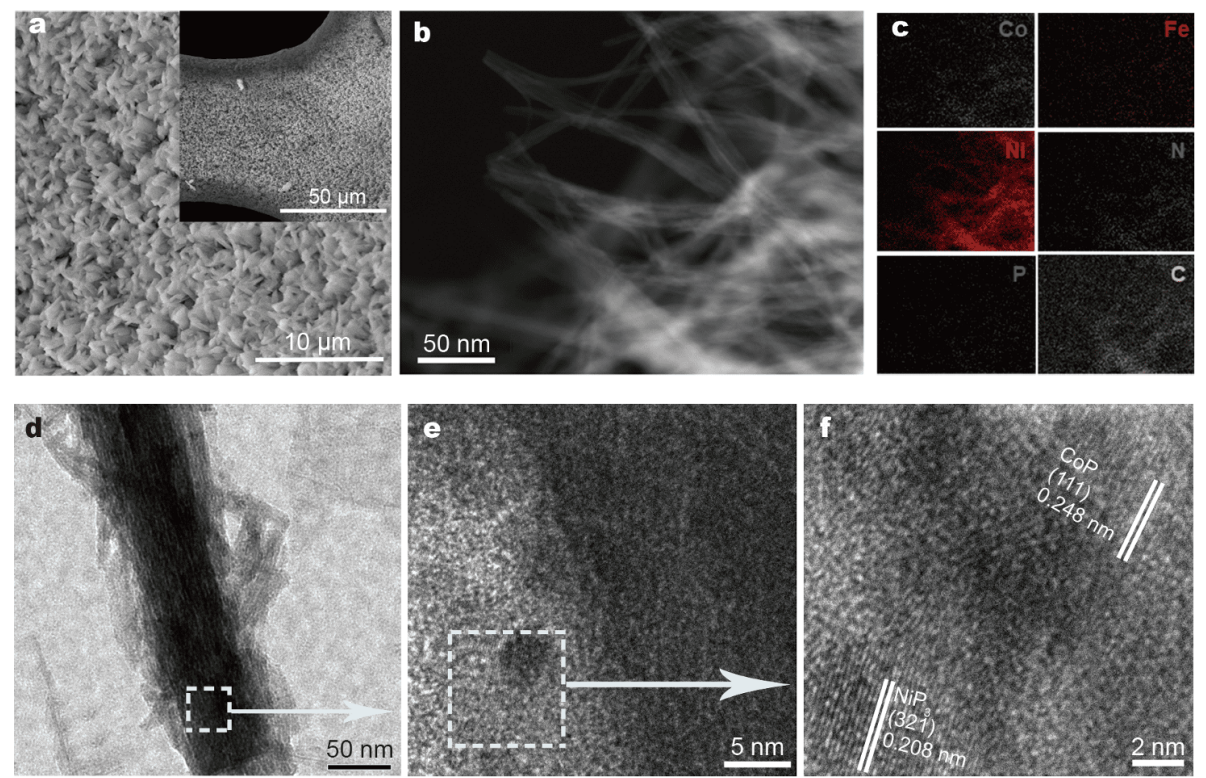

Figure 2 (a) SEM images of NiFe LDH@CoP/NiP . (b) TEM and (c) corresponding elemental mapping images. (d) TEM and (e, f) high-resolution TEM images of NiFe LDH@CoP/NiP .
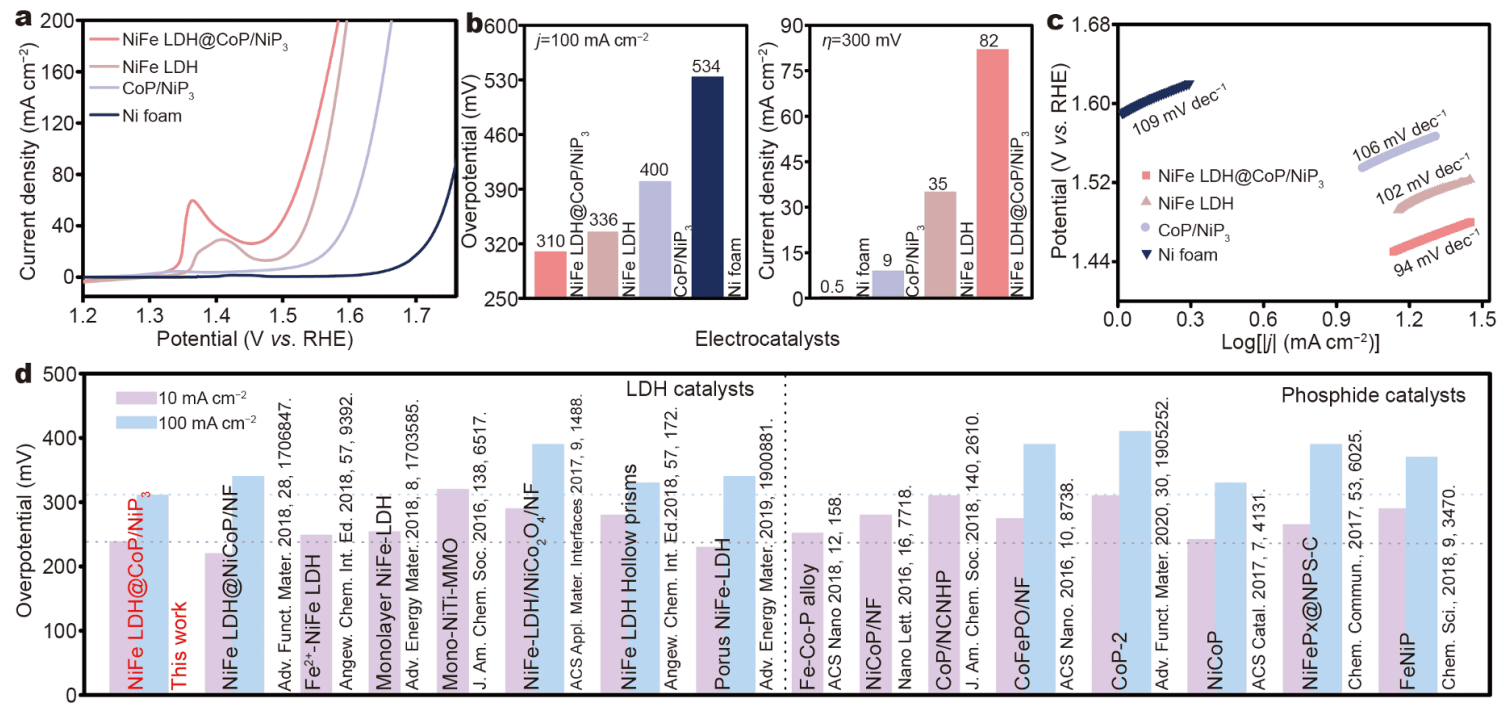

Electrocatalysts

Figure 3 (a) OER polarization curves in $1.0 \mathrm{~mol} \mathrm{~L}^{-1} \mathrm{KOH}$. (b) Overpotentials at $100 \mathrm{~mA} \mathrm{~cm}{ }^{-2}$ (left) and current densities at $\eta=300 \mathrm{mV}$ (right) of different samples. (c) Tafel plots of different samples. (d) The overpotentials of recently reported electrocatalysts in $1.0 \mathrm{~mol} \mathrm{~L} \mathrm{KOH}^{-1} \mathrm{~K}$

with $\mathrm{NiFe} \mathrm{LDH}$ and $\mathrm{CoP} / \mathrm{NiP}_{3}$. In particular, $\mathrm{NiFe}$ $\mathrm{LDH} @ \mathrm{CoP} / \mathrm{NiP}_{3}$ only required an overpotential of $300 \mathrm{mV}$ to reach a current density of $82 \mathrm{~mA} \mathrm{~cm}^{-2}$, which is $164.0,9.1$ and 2.3 times that of $\mathrm{Ni}$ foam, $\mathrm{CoP} / \mathrm{NiP}_{3}$ and $\mathrm{NiFe} \mathrm{LDH}$, respectively (Fig. 3b). The Tafel slope value of $\mathrm{NiFe} \mathrm{LDH} @ \mathrm{CoP} / \mathrm{NiP}_{3}$ was $94 \mathrm{mV} \mathrm{dec}{ }^{-1}$ (Fig. 3c), which indicates faster kinetics than the other samples [39].
Based on the above result, the enhanced OER activity should be attributed to the synergy of $\mathrm{CoP} / \mathrm{NiP}_{3}$ and $\mathrm{NiFe}$ LDH [40]. Compared with both LDH catalysts and phosphide catalysts reported recently, NiFe LDH@CoP/ $\mathrm{NiP}_{3}$ exhibited a relatively favorable performance at both 10 and $100 \mathrm{~mA} \mathrm{~cm}^{-2}$ (Fig. 3d and Tables S4 and S5). The $\mathrm{NiFe} \mathrm{LDH} @ \mathrm{CoP} / \mathrm{NiP}_{3}$ demonstrated good stability for 
more than $70 \mathrm{~h}$ at an overpotential of $300 \mathrm{mV}$ (Fig. S10).

It has been reported that phosphides exhibit self-reconstruction phenomena during the OER process [4143]. The reconstructed catalysts, with oxyhydroxides on the surface, inherit the advantages of nanostructures, which are stable and act as the true active species [40]. To investigate the reconstruction of $\mathrm{NiFe} \mathrm{LDH} @ \mathrm{CoP} / \mathrm{NiP}_{3}$ during OER, XPS and Raman spectra were recorded before and after OER. In Fig. $4 \mathrm{a}$, the Co $2 \mathrm{p}_{3 / 2}$ peaks at 774.8, 780.3 and $796.4 \mathrm{eV}$ correspond to the $\mathrm{Co}^{\circ}$, oxidized $\mathrm{Co}^{2+} / \mathrm{Co}^{3+}$, and satellite peak, respectively [44]. The weakened $\mathrm{Co}^{0}$ peak of NiFe LDH@CoP/NiP 3 after OER indicates the improved oxidation state of the Co species. As shown in Fig. $4 \mathrm{~b}$, the binding energies of $\mathrm{Ni} 2 \mathrm{p}_{3 / 2}$ $(854.9 \mathrm{eV})$ and $\mathrm{Ni} 2 \mathrm{p}_{1 / 2}(872.7 \mathrm{eV})$ shift to 855.3 and $873.0 \mathrm{eV}$, respectively, demonstrating the improved oxidation state after OER [45]. In the O 1s spectra of NiFe $\mathrm{LDH} @ \mathrm{CoP} / \mathrm{NiP}_{3}$ (Fig. 4c), the peaks at 530.4 and $531.5 \mathrm{eV}$ are attributed to $\mathrm{M}-\mathrm{O}$ bonds ( $\mathrm{M}$ representing metal) and oxygen defects in LDH, respectively. The peak at $532.5 \mathrm{eV}$ corresponds to the adsorbed $\mathrm{O}$ resulting from hydroxyl groups (such as adsorbed $\mathrm{H}_{2} \mathrm{O}$ ) [46]. In the Raman spectra of NiFe LDH@CoP/NiP , the peaks located at 188,321 and $534 \mathrm{~cm}^{-1}$ correspond to $\mathrm{O}-\mathrm{M}-\mathrm{O}$, $\mathrm{O}-\mathrm{H}$ and $\mathrm{M}-\mathrm{O}-\mathrm{M}$ vibrations in $\mathrm{LDH}$, respectively (Fig. 4d and Table S6) [47-49]. After the OER, the peaks at 188 and $321 \mathrm{~cm}^{-1}$ were not present because of the conversion of hydroxides into oxyhydroxides. Under anodic potentials, the hydrophilic, conductive and chemically stable $\mathrm{M}-\mathrm{OOH}$ may be formed. This could serve as the real active composition to boost OER activity [5053]. The crystal structure and surface morphology of NiFe $\mathrm{LDH} @ \mathrm{CoP} / \mathrm{NiP}_{3}$ after OER were also investigated. After the OER process, the phosphide peak intensity was reduced, which may be attributed to the formation of amorphous oxyhydroxides. In the SEM images (Fig. S11a, b), the initial arborized structure was seen to have transformed into a finer flower-like structure after the OER. This change in surface morphology also confirmed the reconstruction of the catalyst, consistent with the afore-described XPS and Raman results. After reconstruction of the phosphides, the $\mathrm{M}-\mathrm{OOH}$ active site was introduced, and the transformed flower-like structure exposes more active sites. These factors significantly improve the catalyst activity.

Subsequently, the HER activity of NiFe LDH@CoP/ $\mathrm{NiP}_{3}$ was evaluated, which demonstrated clear superiority over those of $\mathrm{CoP} / \mathrm{NiP}_{3}$ and $\mathrm{NiFe} \mathrm{LDH}$ (Fig. 5a). The overpotentials of NiFe LDH@CoP/NiP 3 at different current densities are listed in Fig. S12. To reach a current density of $50 \mathrm{~mA} \mathrm{~cm}^{-2}$, the required overpotential was only 206 mV (Fig. 5b left). For NiFe LDH@CoP/NiP 3 , an
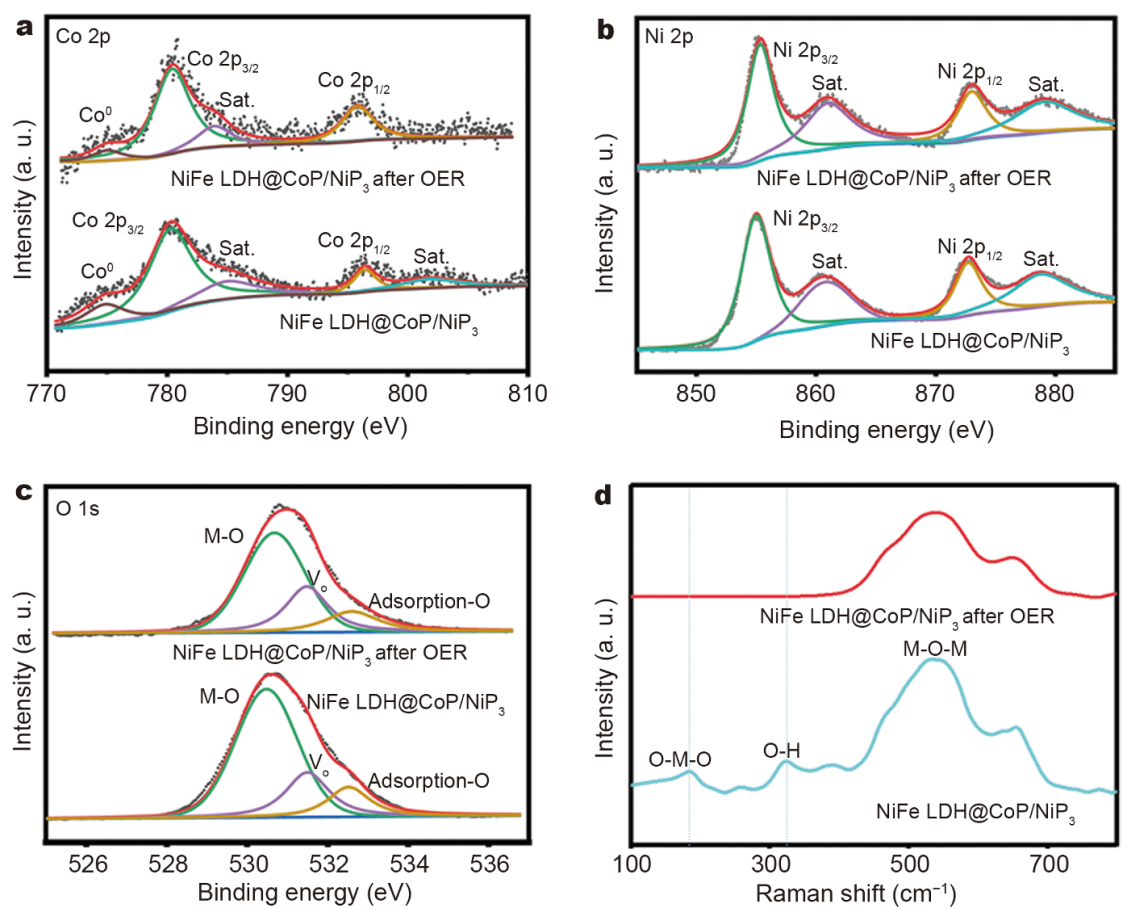

Figure $4(\mathrm{a}-\mathrm{c})$ The corresponding high-resolution XPS spectra of Co 2p, Ni 2p and O 1s. (d) Raman spectra of NiFe LDH@CoP/NiP 2 . 

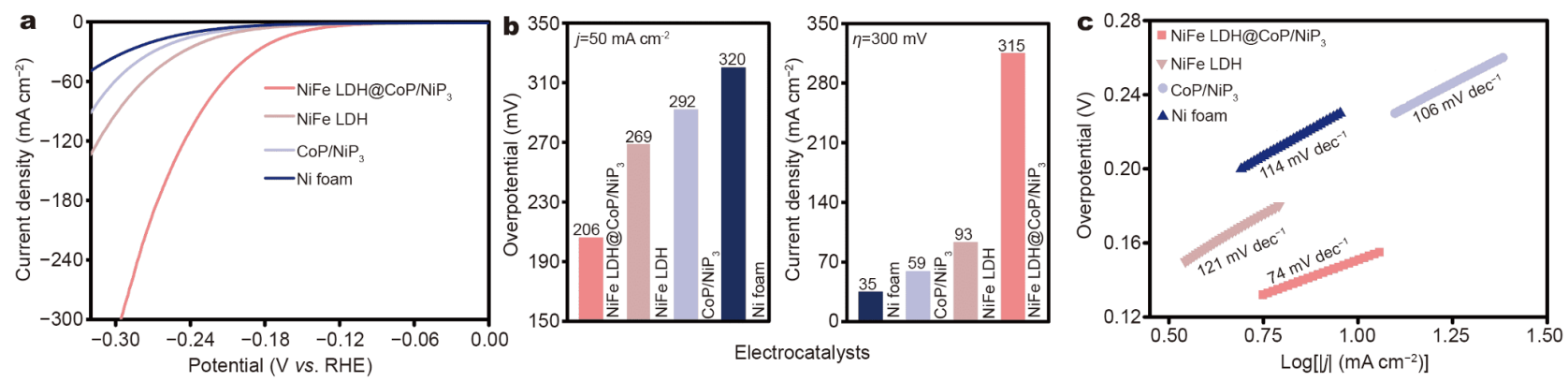

Figure 5 (a) HER polarization curves in $1.0 \mathrm{~mol} \mathrm{~L}^{-1} \mathrm{KOH}$. (b) Overpotentials at $50 \mathrm{~mA} \mathrm{~cm}{ }^{-2}$ (left) and current densities at $\eta=300 \mathrm{mV}$ (right) of various samples. (c) Tafel plots of different samples.
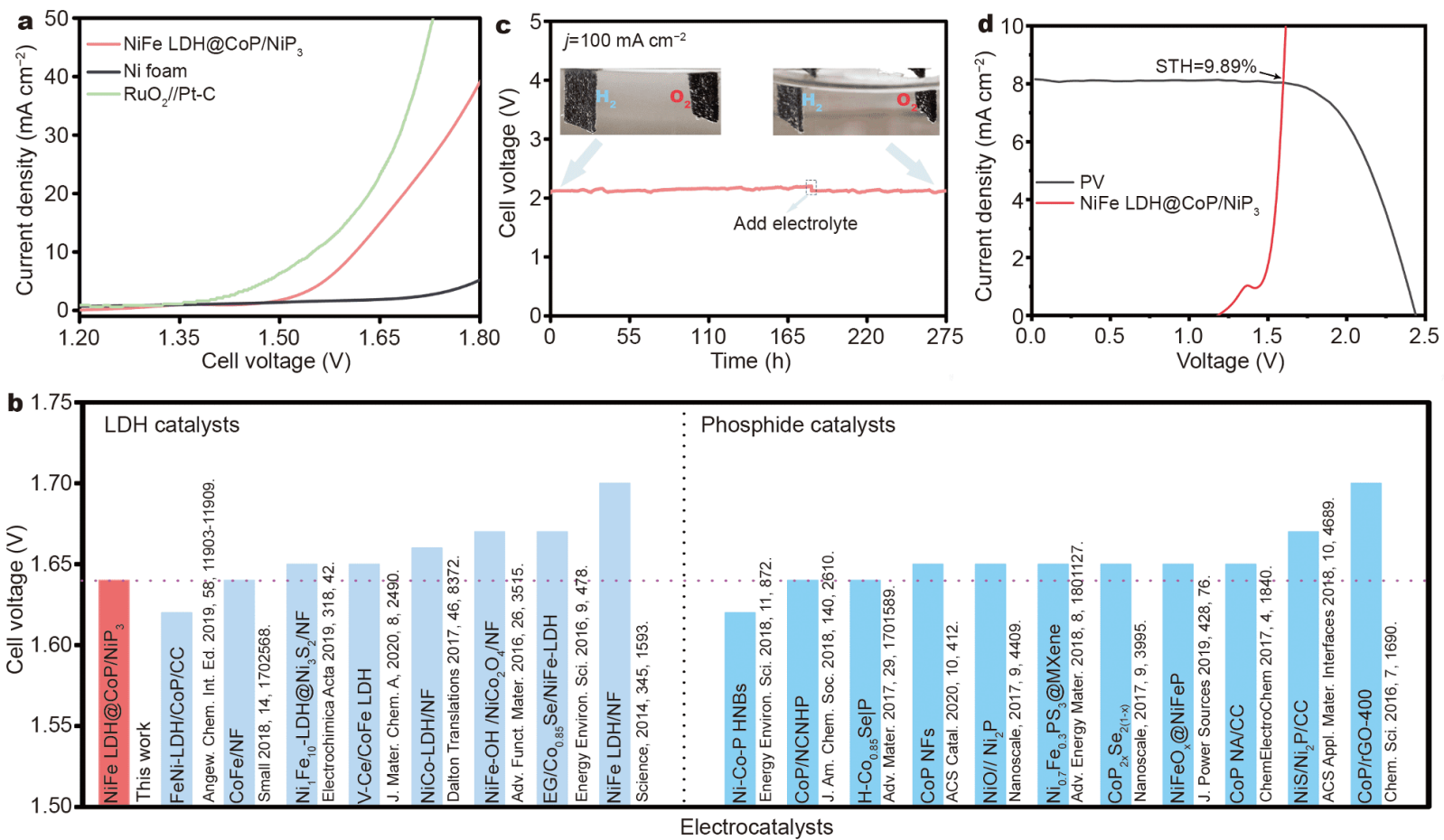

Figure 6 (a) Overall water splitting polarization curves in $1.0 \mathrm{~mol} \mathrm{~L}^{-1} \mathrm{KOH}$. (b) The required cell voltage of electrocatalysts at $10 \mathrm{~mA} \mathrm{~cm}{ }^{-2}$ in recent years. (c) Stability test of $\mathrm{NiFe} \mathrm{LDH} @ \mathrm{CoP} / \mathrm{NiP}_{3}$. Insets: photograph evolving from the electrodes at the beginning of stability test and after $275 \mathrm{~h}$. (d) $J$ $V$ curve of a solar cell and the polarization curve of $\mathrm{NiFe} \mathrm{LDH} @ \mathrm{CoP} / \mathrm{NiP}_{3}$ for water splitting in a two-electrode system.

overpotential of $300 \mathrm{mV}$ resulted in a current density of $315 \mathrm{~mA} \mathrm{~cm}^{-2}$, which is $9.0,5.3$ and 3.4 times that of $\mathrm{Ni}$ foam, $\mathrm{CoP} / \mathrm{NiP}_{3}$, and $\mathrm{NiFe} \mathrm{LDH}$, respectively (Fig. 5b right). Fig. $5 \mathrm{c}$ shows that the Tafel slope of $\mathrm{NiFe}$ $\mathrm{LDH} @ \mathrm{CoP} / \mathrm{NiP}_{3}$ is also the smallest $\left(74 \mathrm{mV} \mathrm{dec}{ }^{-1}\right)$, indicating the Volmer-Heyrovsky mechanism [54].

Considering the above results, NiFe LDH@CoP/NiP 3 shows potential as a bifunctional OER/HER electrocatalyst. We then explored the overall water splitting performance (Fig. S13). Using NiFe LDH@CoP/NiP 3 as both the cathode and anode, a cell voltage of $1.64 \mathrm{~V}$ was required to reach a current density of $10 \mathrm{~mA} \mathrm{~cm}^{-2}$ (Fig. 6a), which is comparable to most of the reported results summarized in Fig. 6b, based on Tables S7 and S8. Notably, the constant current test at $100 \mathrm{~mA} \mathrm{~cm}^{-2}$ lasted for $275 \mathrm{~h}$ with negligible activity loss (Fig. 6c). As seen in the inset in Fig. $6 c, \mathrm{H}_{2}$ bubbles at the cathode and the $\mathrm{O}_{2}$ bubbles at the anode were continuously produced during the entire electrolysis process, further illustrating the excellent stability of the $\mathrm{NiFe} \mathrm{LDH} @ \mathrm{CoP} / \mathrm{NiP}_{3}$ electrode. The high durability of this water splitting system undoubtedly makes it promising for application. We 
speculated that, as a self-supporting electrode, the $\mathrm{Ni}$ foam achieved close contact with the catalyst layer, which reduced the charge transfer resistance and enhanced the durability under large current densities [55]. Additionally, the three-dimensional porous structure increased the area of exposed active sites, hence boosting the catalytic activity [56]. Then, we designed a simple solar-driven water splitting system, which comprised a commercial Si solar plane $\left(16 \mathrm{~cm}^{2}\right)$ and electrodes. Fig. S14a, b show the electrolyzed water test, which used NiFe LDH@CoP/NiP as both the cathode and anode in $1.0 \mathrm{~mol} \mathrm{~L}^{-1} \mathrm{KOH}$ solution under Xe light irradiation as simulated sunlight. $\mathrm{H}_{2}$ and $\mathrm{O}_{2}$ were spontaneously produced under the simulated solar irradiation. From the current-voltage $(J-V)$ curve of the solar cell and the polarization curve of the water splitting system, the operating current density at $1.59 \mathrm{~V}$ was calculated to be $\sim 8 \mathrm{~mA} \mathrm{~cm}^{-2}$, which corresponded to an STH efficiency of $9.89 \%$ (Fig. 6d) [57,58]. Thus, NiFe LDH@CoP/NiP 3 displayed potential to be used in solar-driven water splitting.

\section{CONCLUSIONS}

In summary, NiFe LDH@CoP/NiP 3 was constructed as a bifunctional OER/HER catalyst, which demonstrated improved performance over the sum of its isolated components. Under alkaline condition, NiFe LDH@CoP/ $\mathrm{NiP}_{3}$ achieved an OER current density of $82 \mathrm{~mA} \mathrm{~cm}^{-2}$ (at an overpotential of $300 \mathrm{mV}$ ), which was 9.1 times that of $\mathrm{CoP} / \mathrm{NiP}_{3}$. Moreover, the reconstruction behavior during the OER was studied. In particular, for overall water splitting, the sample displayed excellent durability for $275 \mathrm{~h}$ at $100 \mathrm{~mA} \mathrm{~cm}^{-2}$. Under Xe light irradiation, the water splitting STH efficiency was $9.89 \%$. A detailed study of the synergistic mechanism between $\mathrm{CoP} / \mathrm{NiP}_{3}$ and $\mathrm{NiFe}$ LDH is currently under way. This work presents the coupling of different active compositions and their synergistic catalytic performance, and can provide a reference for designing bifunctional electrocatalysts.

\section{Received 25 August 2020; accepted 17 November 2020;} published online 2 February 2021

1 Zhang M, Li X, Zhao J, et al. Surface/interface engineering of noble-metals and transition metal-based compounds for electrocatalytic applications. J Mater Sci Tech, 2020, 38: 221-236

2 Lei Y, Wang Y, Liu Y, et al. Designing atomic active centers for hydrogen evolution electrocatalysts. Angew Chem Int Ed, 2020, 59: 20794-20812

3 Zhang N, Ye C, Yan $\mathrm{H}$, et al. Single-atom site catalysts for environmental catalysis. Nano Res, 2020, 13: 3165-3182

4 Chen Y, Ji S, Sun W, et al. Engineering the atomic interface with single platinum atoms for enhanced photocatalytic hydrogen production. Angew Chem Int Ed, 2020, 59: 1295-1301

5 Cai Z, Li L, Zhang Y, et al. Amorphous nanocages of $\mathrm{Cu}-\mathrm{Ni}-\mathrm{Fe}$ hydr(oxy)oxide prepared by photocorrosion for highly efficient oxygen evolution. Angew Chem Int Ed, 2019, 58: 4189-4194

6 Chen G, Zhu Y, Chen HM, et al. An amorphous nickel-iron-based electrocatalyst with unusual local structures for ultrafast oxygen evolution reaction. Adv Mater, 2019, 31: 1900883

7 Anantharaj S, Ede SR, Sakthikumar K, et al. Recent trends and perspectives in electrochemical water splitting with an emphasis on sulfide, selenide, and phosphide catalysts of $\mathrm{Fe}, \mathrm{Co}$, and $\mathrm{Ni}$ : A review. ACS Catal, 2016, 6: 8069-8097

8 Shang H, Sun W, Sui R, et al. Engineering isolated $\mathrm{Mn}-\mathrm{N}_{2} \mathrm{C}_{2}$ atomic interface sites for efficient bifunctional oxygen reduction and evolution reaction. Nano Lett, 2020, 20: 5443-5450

9 Wang Q, Lei Y, Wang Y, et al. Atomic-scale engineering of chemical-vapor-deposition-grown 2D transition metal dichalcogenides for electrocatalysis. Energy Environ Sci, 2020, 13: 1593-1616

10 Yang J, Li W, Wang D, et al. Electronic metal-support interaction of single-atom catalysts and applications in electrocatalysis. Adv Mater, 2020, 32: 2003300

11 Dou Y, He CT, Zhang L, et al. Approaching the activity limit of $\mathrm{CoSe}_{2}$ for oxygen evolution via Fe doping and Co vacancy. Nat Commun, 2020, 11: 1664

12 Liu Q, Wang Q, Wang J, et al. $\mathrm{TpyCo}^{2+}$-based coordination polymers by water-induced gelling trigged efficient oxygen evolution reaction. Adv Funct Mater, 2020, 30: 2000593

13 Wang Q, Xue X, Lei $\mathrm{Y}$, et al. Engineering of electronic states on $\mathrm{Co}_{3} \mathrm{O}_{4}$ ultrathin nanosheets by cation substitution and anion vacancies for oxygen evolution reaction. Small, 2020, 16: 2001571

14 Ling T, Zhang T, Ge B, et al. Well-dispersed nickel- and zinctailored electronic structure of a transition metal oxide for highly active alkaline hydrogen evolution reaction. Adv Mater, 2019, 31: 1807771

15 Liu R, Wang Y, Liu D, et al. Water-plasma-enabled exfoliation of ultrathin layered double hydroxide nanosheets with multivacancies for water oxidation. Adv Mater, 2017, 29: 1701546

16 Fang G, Wang Q, Zhou J, et al. Metal organic framework-templated synthesis of bimetallic selenides with rich phase boundaries for sodium-ion storage and oxygen evolution reaction. ACS Nano, 2019, 13: 5635-5645

17 Qin JF, Yang M, Chen TS, et al. Ternary metal sulfides MoCoNiS derived from metal organic frameworks for efficient oxygen evolution. Int J Hydrogen Energy, 2020, 45: 2745-2753

18 Zhang Y, Fu L, Shu Z, et al. Substitutional doping for aluminosilicate mineral and superior water splitting performance. Nanoscale Res Lett, 2017, 12: 456

19 Lei C, Zhou W, Feng Q, et al. Charge engineering of $\mathrm{Mo}_{2} \mathrm{C} @$ defectrich $\mathrm{N}$-doped carbon nanosheets for efficient electrocatalytic $\mathrm{H}_{2}$ evolution. Nano-Micro Lett, 2019, 11: 45

20 Zhang R, Tang C, Kong R, et al. Al-doped CoP nanoarray: a durable water-splitting electrocatalyst with superhigh activity. Nanoscale, 2017, 9: 4793-4800

21 You B, Sun Y. Innovative strategies for electrocatalytic water splitting. Acc Chem Res, 2018, 51: 1571-1580

22 Chen Z, Duan X, Wei W, et al. Boride-based electrocatalysts: emerging candidates for water splitting. Nano Res, 2020, 13: 293314

23 Wang X, Vasileff A, Jiao Y, et al. Electronic and structural engineering of carbon-based metal-free electrocatalysts for water splitting. Adv Mater, 2019, 31: 1803625 
24 Li X, Rong $\mathrm{H}$, Zhang J, et al. Modulating the local coordination environment of single-atom catalysts for enhanced catalytic performance. Nano Res, 2020, 13: 1842-1855

25 Mishra IK, Zhou H, Sun J, et al. Hierarchical $\mathrm{CoP} / \mathrm{Ni}_{5} \mathrm{P}_{4} / \mathrm{CoP}$ microsheet arrays as a robust $\mathrm{pH}$-universal electrocatalyst for efficient hydrogen generation. Energy Environ Sci, 2018, 11: 22462252

26 Huang J, Li Y, Zhang Y, et al. Identification of key reversible intermediates in self-reconstructed nickel-based hybrid electrocatalysts for oxygen evolution. Angew Chem Int Ed, 2019, 58: 17458-17464

27 Cao J, Wang K, Chen J, et al. Nitrogen-doped carbon-encased bimetallic selenide for high-performance water electrolysis. NanoMicro Lett, 2019, 11: 67

28 Zhang X, Zhao Y, Zhao Y, et al. A simple synthetic strategy toward defect-rich porous monolayer NiFe-layered double hydroxide nanosheets for efficient electrocatalytic water oxidation. Adv Energy Mater, 2019, 9: 1900881

29 Zhang Z, Zhou D, Zhou L, et al. NiFe LDH-CoPc/CNTs as novel bifunctional electrocatalyst complex for zinc-air battery. Ionics, 2018, 24: 1709-1714

30 Wu N, Lei Y, Wang Q, et al. Facile synthesis of FeCo@NC coreshell nanospheres supported on graphene as an efficient bifunctional oxygen electrocatalyst. Nano Res, 2017, 10: 2332-2343

31 Yang Y, Zhang W, Xiao Y, et al. $\mathrm{CoNiSe}_{2}$ heteronanorods decorated with layered-double-hydroxides for efficient hydrogen evolution. Appl Catal B-Environ, 2019, 242: 132-139

32 Liang H, Gandi AN, Xia C, et al. Amorphous NiFe-OH/NiFeP electrocatalyst fabricated at low temperature for water oxidation applications. ACS Energy Lett, 2017, 2: 1035-1042

33 He K, Tadesse Tsega T, Liu X, et al. Utilizing the space-charge region of the FeNi-LDH/CoP p-n junction to promote performance in oxygen evolution electrocatalysis. Angew Chem Int Ed, 2019, 58: 11903-11909

34 Zhang H, Li X, Hähnel A, et al. Bifunctional heterostructure assembly of NiFe LDH nanosheets on NiCoP nanowires for highly efficient and stable overall water splitting. Adv Funct Mater, 2018, 28: 1706847

35 Chen L, He C, Wang R, et al. Potential active sites of Mo single atoms for electrocatalytic reduction of $\mathrm{N}_{2}$. Chin Chem Lett, 2021, 32: $53-56$

36 Sun $\mathrm{T}, \mathrm{Xu} \mathrm{L}$, Wang $\mathrm{D}$, et al. Metal organic frameworks derived single atom catalysts for electrocatalytic energy conversion. Nano Res, 2019, 12: 2067-2080

37 Chen L, Song Y, Liu Y, et al. NiCoP nanoleaves array for electrocatalytic alkaline $\mathrm{H}_{2}$ evolution and overall water splitting. J Energy Chem, 2020, 50: 395-401

38 Zhang W, Li D, Zhang L, et al. NiFe-based nanostructures on nickel foam as highly efficiently electrocatalysts for oxygen and hydrogen evolution reactions. J Energy Chem, 2019, 39: 39-53

39 Niu S, Jiang WJ, Wei Z, et al. Se-doping activates FeOOH for costeffective and efficient electrochemical water oxidation. J Am Chem Soc, 2019, 141: 7005-7013

$40 \mathrm{Xu} \mathrm{X}$, Song F, Hu X. A nickel iron diselenide-derived efficient oxygen-evolution catalyst. Nat Commun, 2016, 7: 12324

$41 \mathrm{Wu}$ T, Sun S, Song J, et al. Iron-facilitated dynamic active-site generation on spinel $\mathrm{CoAl}_{2} \mathrm{O}_{4}$ with self-termination of surface reconstruction for water oxidation. Nat Catal, 2019, 2: 763-772

$42 \mathrm{He} \mathrm{Q}$, Wan $\mathrm{Y}$, Jiang $\mathrm{H}$, et al. Nickel vacancies boost reconstruction in nickel hydroxide electrocatalyst. ACS Energy Lett, 2018, 3:
1373-1380

43 Asnavandi M, Yin Y, Li Y, et al. Promoting oxygen evolution reactions through introduction of oxygen vacancies to benchmark NiFe-OOH catalysts. ACS Energy Lett, 2018, 3: 1515-1520

44 Liu T, Li P, Yao N, et al. CoP-doped MOF-based electrocatalyst for $\mathrm{pH}$-universal hydrogen evolution reaction. Angew Chem Int Ed, 2019, 58: 4679-4684

45 Yu L, Zhou H, Sun J, et al. Hierarchical Cu@CoFe layered double hydroxide core-shell nanoarchitectures as bifunctional electrocatalysts for efficient overall water splitting. Nano Energy, 2017, 41: 327-336

46 Lei $\mathrm{Y}$, Shi Q, Han $\mathrm{C}$, et al. N-doped graphene grown on silk cocoon-derived interconnected carbon fibers for oxygen reduction reaction and photocatalytic hydrogen production. Nano Res, 2016, 9: 2498-2509

47 Konkena B, Masa J, Botz AJR, et al. Metallic $\mathrm{NiPS}_{3} @ \mathrm{NiOOH}$ coreshell heterostructures as highly efficient and stable electrocatalyst for the oxygen evolution reaction. ACS Catal, 2017, 7: 229-237

48 Long X, Xiao S, Wang Z, et al. Co intake mediated formation of ultrathin nanosheets of transition metal $\mathrm{LDH}-$ an advanced electrocatalyst for oxygen evolution reaction. Chem Commun, 2015, 51: $1120-1123$

49 Meng X, Han J, Lu L, et al. $\mathrm{Fe}^{2+}$-doped layered double (Ni, Fe) hydroxides as efficient electrocatalysts for water splitting and selfpowered electrochemical systems. Small, 2019, 15: 1902551

50 Bai X, Ren Z, Du S, et al. In-situ structure reconstitution of $\mathrm{NiCo}_{2} \mathrm{P}$ for enhanced electrochemical water oxidation. Sci Bull, 2017, 62: $1510-1518$

51 Zhang FS, Wang JW, Luo J, et al. Extraction of nickel from NiFe$\mathrm{LDH}$ into $\mathrm{Ni}_{2} \mathrm{P} @ \mathrm{NiFe}$ hydroxide as a bifunctional electrocatalyst for efficient overall water splitting. Chem Sci, 2018, 9: 1375-1384

$52 \mathrm{Gu} \mathrm{C}, \mathrm{Hu} \mathrm{S}$, Zheng X, et al. Synthesis of sub-2 nm iron-doped $\mathrm{NiSe}_{2}$ nanowires and their surface-confined oxidation for oxygen evolution catalysis. Angew Chem Int Ed, 2018, 57: 4020-4024

53 Jiang J, Sun F, Zhou S, et al. Atomic-level insight into superefficient electrocatalytic oxygen evolution on iron and vanadium co-doped nickel (oxy)hydroxide. Nat Commun, 2018, 9: 2885

54 Gao Q, Zhang W, Shi Z, et al. Structural design and electronic modulation of transition-metal-carbide electrocatalysts toward efficient hydrogen evolution. Adv Mater, 2019, 31: 1802880

55 Yang Z, Liang X. Self-magnetic-attracted $\mathrm{Ni}_{x} \mathrm{Fe}_{(1-x)} @ \mathrm{Ni}_{x} \mathrm{Fe}_{(1-x)} \mathrm{O}$ nanoparticles on nickel foam as highly active and stable electrocatalysts towards alkaline oxygen evolution reaction. Nano Res, 2020, 13: 461-466

56 Wang Y, Liu Y, Liu W, et al. Regulating the coordination structure of metal single atoms for efficient electrocatalytic $\mathrm{CO}_{2}$ reduction. Energy Environ Sci, 2020, 13: 4609-4624

57 Hsu SH, Miao J, Zhang L, et al. An earth-abundant catalyst-based seawater photoelectrolysis system with $17.9 \%$ solar-to-hydrogen efficiency. Adv Mater, 2018, 30: 1707261

58 Kuang Y, Kenney MJ, Meng Y, et al. Solar-driven, highly sustained splitting of seawater into hydrogen and oxygen fuels. Proc Natl Acad Sci USA, 2019, 116: 6624-6629

Acknowledgements This work was financially supported by Hunan Provincial Science and Technology Plan Project (2017TP1001 and 2020JJ4710), the National Key R\&D Program of China (2018YFB0704100) and the State Key Laboratory Fund.

Author contributions Song C and Liu Y performed the experiments 
and sample preparation; Song C and Wang Y wrote the paper with support from Lei $\mathrm{Y}$; Tang $\mathrm{S}$ was responsible for the data processing; $\mathrm{Li}$ $\mathrm{W}$ and Zeng J contributed to the theoretical analysis; Li Q, Chen L and Peng $\mathrm{H}$ provided constructive suggestions. All authors contributed to the general discussion.

Conflict of interest The authors declare no conflict of interest.

Supplementary information Supporting data are available in the online version of the paper.

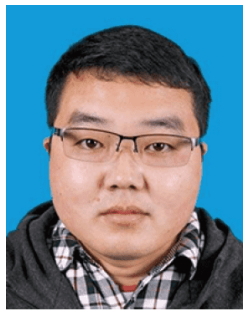

Chengye Song received his Bachelor degree from Jiangxi Science and Technology Normal University in 2016. He is currently pursuing his Master degree under the supervision of Prof. Yongpeng Lei and Prof. Wenkui Li.

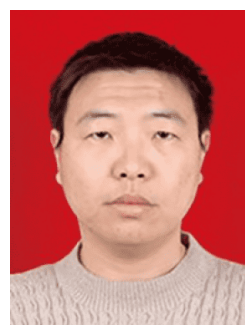

Wenkui Li received his BS degree (1998) in Hebei University and Master degree (2001) in Hunan University, and his $\mathrm{PhD}$ degree (2004) in Shanghai Institute of Ceramics, Chinese Academy of Sciences with Prof. Hanrui Zhuang. He joined the faculty of Jiangxi Province Key Laboratory of Surface Engineering, Jiangxi Science \& Technology Normal University in 2004 as a full professor.

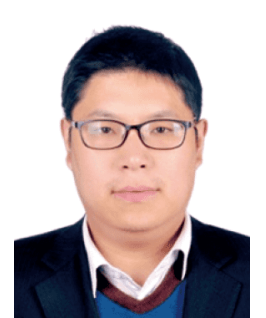

Yongpeng Lei received his BS degree (2003) and Master degree (2006) in National University of Defense Technology, and his PhD degree (2011) in National University of Defense Technology with Prof. Yingde Wang. He started the study of functional nanomaterials at the Department of Chemistry, Tsinghua University in 2011, under the guidance of Prof. Yadong Li. He joined the faculty of the State Key Laboratory of Powder Metallurgy, Central South University in 2017 as a full professor.

\section{层状镍铁双氢氧化物与金属磷化物耦合实现高效 析氧和稳定的全解水}

宋成叶 ${ }^{1,2 \dagger}$, 刘毅 ${ }^{1 \dagger}$, 王裕超 ${ }^{1,4 \dagger}$, 唐帅豪 ${ }^{1,5}$, 李文鬼斗 ${ }^{*}$, 李倩 1,4 , 曾坚 ${ }^{1,5}$, 陈雷 $^{3}$, 彭宏程 $^{3}$, 雷永鹏 $^{1,3,6^{*}}$

摘要 研制具有优良稳定性的高活性析氧反应(OER)电催化剂是 一个巨大的挑战. 这项工作构建了层状镍铁双氢氧化物修饰的磷 化物( $\left.\mathrm{NiFe} \mathrm{LDH} @ \mathrm{CoP} / \mathrm{NiP}_{3}\right)$, 其在碱性介质中呈现出了令人满意 的OER活性和良好的全解水稳定性．在 $300 \mathrm{mV}$ 的过电位下, $\mathrm{NiFe}$ $\mathrm{LDH} @ \mathrm{CoP} / \mathrm{NiP}_{3}$ 的电流密度为 $82 \mathrm{~mA} \mathrm{~cm}^{-2}$, 分别是 $\mathrm{CoP} / \mathrm{NiP}_{3}$ 和 $\mathrm{NiFe}$ LDH的9.1倍和2.3倍. 通过X射线光电子能谱、拉曼和扫描电 镜表征, 研究了 OER过程中的重构行为. 氢析出性能测试也论证了 $\mathrm{NiFe} \mathrm{LDH}$ 与 $\mathrm{CoP} / \mathrm{NiP}_{3}$ 之间的协同效应. 此外, $\mathrm{NiFe} \mathrm{LDH} @ \mathrm{CoP} /$ $\mathrm{NiP}_{3}$ 同时作为阴极和阳极进行全解水时, 可以维持 $100 \mathrm{~mA} \mathrm{~cm}$ 的 高电流密度超过275小时. 此外, 在氙灯的照射下, 太阳能驱动的水 分解可以实现 $9.89 \%$ 的光产氢效率. 这项工作实现了不同活性成分 间的耦合, 为双功能电催化剂的设计提供了参考. 